\title{
Extratos vegetais sobre Hypothenemus hampei (Coleoptera: Curculionidae) e Beauveria bassiana
}

\author{
Plant extracts on Hypothenemus hampei (Coleoptera: \\ Curculionidae) and Beauveria bassiana
}

\author{
Janaina Zorzetti ${ }^{1 *}$; Pedro Manuel Oliveira Janeiro Neves ${ }^{2}$; Kelly Christiane \\ Constanski ${ }^{3}$; Patrícia Helena Santoro ${ }^{4}$; Inês Cristina Batista Fonseca ${ }^{2}$
}

\begin{abstract}
Resumo
Visando alternativas ao uso de agrotóxicos no controle de Hypothenemus hampei, o objetivo deste trabalho foi avaliar o potencial de extratos vegetais aquosos e etanólicos de Moringa oleifera (moringa) e Tephrosia purpurea (tephrosia) (sementes, folhas e raízes) e Melia azedarach,(cinamomo) Nerium oleander, (espirradeira) Azadirachta indica (nim) (apenas folhas), na mortalidade e repelência de H. hampei, e sua compatibilidade com Beauveria bassiana, importante inimigo natural desta praga. Para avaliar a mortalidade, ofereceram-se aos adultos, folhas de cafeeiro (Coffea arabica L) tratadas por imersão em solução de endosulfan e em extratos vegetais na concentração de $10 \%$. A repelência foi avaliada em testes com e sem chance de escolha, entre frutos de cafeeiro tratados e não tratados. A compatibilidade entre os extratos e Beauveria bassiana (CG 452) foi analisada quantificando a germinação, unidades formadoras de colônias, crescimento vegetativo e produção/produtividade de conídios. As maiores mortalidades foram observadas quando folhas foram tratadas com o extrato etanólico das de T. purpurea (folhas) que não diferiu do endosulfan, e de extrato aquoso e etanólico da semente de M. oleifera. Em testes com chance de escolha, todos os extratos etanólicos possuíram ação repelente, sendo que a maior repelência foi causada por M. oleifera (raiz) e T. purpurea (semente). Os extratos aquosos de folhas e semente de $M$. oleifera e de folhas de $N$. oleander apresentaram a maior repelência. Nos ensaios sem chance de escolha o maior nível de repelência foi para frutos de cafeeiro tratados com A. indica (folhas). $\mathrm{O}$ extrato etanólico de folhas de $M$. oleifera afetou negativamente a germinação. Estes estudos mostraram o potencial desses extratos para uso a campo como uma alternativa ao controle químico, sendo também seletivos para B. bassiana.
\end{abstract}

Palavras-chave: Broca do cafeeiro, plantas inseticidas, endosulfan, extrato etanólico, extrato aquoso

\begin{abstract}
Looking for alternatives to pesticides for Hypothenemus hampei control, the objective of this study was to evaluate the potential of aqueous and ethanolic plant extracts of Moringa oleifera (Moringa) and Tephrosia purpurea (tephrosia) (seeds, leaves and roots) and Melia azedarach (cinnamon), Nerium oleander (oleander) and Azadirachta indica (neem) (leaves only), on mortality and repellency of $H$. hampei and its compatibility with Beauveria bassiana, an important natural enemy of this pest. To assess the mortality, coffee leaves (Coffea arabica L) were treated by immersion in a solution of endosulfan and plant extracts at a concentration of $10 \%$ and then offered to adults of $H$. hampei. The repellency was evaluated in multiple-choice tests and in no-choice tests among coffee fruit treated and untreated
\end{abstract}

1 Eng ${ }^{\mathrm{o}} \mathrm{Agr}^{\mathrm{O}}$ Doutoranda em Agronomia, Universidade Estadual de Londrina, UEL, Londrina, PR. E-mail: jzorzetti@hotmail.com

2 Profs. Drs. do Dept ${ }^{\circ}$ de Agronomia da UEL, Londrina, PR. E-mail: pedroneves@uel.br; inescbf@uel.br

3 Bióloga, Doutoranda em Agronomia, UEL, Londrina, PR. E-mail: kconstanski@hotmail.com

4 Eng ${ }^{\text {Agr }}{ }^{\text {O }}$ Pesquisadora do Instituto Agronômico do Paraná, IAPAR, Londrina, PR. E-mail: ph_santoro@yahoo.com.br Autor para correspondência 
The compatibility between extracts and Beauveria bassiana (CG 452) was analyzed by quantifying germination, colony forming units, growth and yield / productivity of conidia. The highest mortalities were observed when leaves were treated with ethanolic extract of $T$. purpurea (leaves) which did not differ from endosulfan, and aqueous and ethanolic extracts from M. oleifera seeds . In free-choice tests, all the ethanolic extracts showed repellent action, being higher for M. oleifera (root) and T. purpurea (seed). The aqueous extracts of $M$. oleifera (leaves and seeds) and $N$. oleander (leaves) showed the highest repellency. In no-choice tests the highest repellency level was for coffee fruits treated with $A$. indica (leaves). The ethanolic extract of $M$. oleifera leaves negatively affected $B$. bassiana germination. These studies showed the potential of these plant extracts for use in the field as an alternative to chemical control, once they are also selective for $B$. bassiana.

Key words: Coffee berry borer, insecticidal plants, endosulfan, ethanolic extract, aqueous extract

\section{Introdução}

A cultura do cafeeiro (Coffea arabica L.) apresenta grande importância econômica e social para o Brasil, que é considerado o maior exportador e segundo maior consumidor de café, liderando a produção mundial com 50,61 milhões de sacas (CONAB, 2012). Entretanto, a cafeicultura apresenta diversos problemas fitossanitários que provocam queda na produtividade e interferem na qualidade da bebida. Entre eles está um variado número de pragas que atacam a planta, sendo responsáveis por danos diretos ao fruto, ou mesmo por danos indiretos às plantas. (GALLO et al., 2002).

Um dos principais agentes limitantes da produção é a broca-do-cafeeiro, Hypothenemus hampei (Ferrari, 1876) (Coleoptera: Curculionidae), que causa danos aos frutos nos diferentes estádios de maturação, como queda de frutos, perda de peso e abertura para entrada de micro-organismos, interferindo na produtividade e na qualidade do produto (REIS, 2002). Atualmente seu controle é realizado com produtos a base de endosulfan, que além de provocar o aparecimento de populações de insetos resistentes (BRUN et. al., 1989; GINGERICH et al., 1996), é classificado como extremamente tóxico e altamente perigoso ao meio ambiente. Sendo assim, a Agência Nacional de Vigilância Sanitária (ANVISA) determinou, em um processo de reavaliação do ingrediente ativo, sua retirada do mercado brasileiro no prazo de quatro anos, contados a partir 31 de julho de 2010 (ANVISA, 2010).
Por estas razões, o controle alternativo da broca é uma necessidade imediata. O uso de espécies vegetais como inseticidas botânicos apresentase como uma alternativa promissora, visto que as plantas produzem vários metabólitos que podem ser prejudiciais aos insetos podendo provocar: mortalidade, repelência, inibição de oviposição e alimentação, alterações no sistema hormonal que promovem distúrbios no desenvolvimento, deformações e infertilidade (SAITO, 2004). Vale ainda ressaltar que os extratos vegetais possuem a vantagem de ter uma rápida degradação no meio ambiente, baixo impacto sobre organismos benéficos e geralmente baixa toxicidade a mamíferos (WIESBROOK, 2004).

Algumas espécies vegetais podem ser testadas no controle da broca-do-cafeeiro, entre elas estão as da família Meliaceae que tem se destacado pelo número de espécies com ação inseticida, sendo que um dos compostos mais promissores é a azadiractina (VALLADARES; DEFAGO; PALACIOS, 1997). Dentre as espécies, a Azadirachta indica (A. Juss, 1830), conhecida como nim, já foi relatada como causadora de diversos efeitos danosos aos insetos, como alterações na oviposição, alimentação e metamorfose (SCHMUTTERER, 1990). Seu efeito foi observado no controle de $H$. hampei, onde houve redução do número de frutos de café brocados e aumento da mortalidade de adultos dentro dos frutos (SPONAGEL, 1994). Outra espécie também pertencente família Meliaceae é Melia azedarach L., popularmente chamada de cinamomo, e muito eficiente no controle de insetos-praga. Seus efeitos 
já foram observados sobre Diabrotica speciosa (Germar, 1824) (Coleoptera: Chrysomelidae) variando de acordo com a parte vegetal utilizada (VENTURA; ITO, 2000).

Estudos realizados com Moringa oleifera Lam., conhecida como moringa, e pertencente a família Moringaceae mostraram o potencial dessa planta no controle de insetos. $\mathrm{O}$ extrato aquoso de sementes apresentou ação larvicida contra Aedes aegypti (L.) (Diptera: Culicidae) sendo capaz de causar $100 \%$ de mortalidade após $24 \mathrm{~h}$ de exposição (FERREIRA et al., 2009). Dentre os compostos responsáveis por essa ação, está a lectina, um tipo de proteína encontrada nas sementes dessa planta, que impede o processo de digestão e absorção de nutrientes nos insetos, causando morte por desnutrição (FRANCOFRAGUAS et al., 2003; SANTOS et al., 2006).

Outra espécie que tem se destacado é a Tephrosia purpurea (Linn.) Pers. (Fabaceae), que contém princípios ativos como os rotenóides, que podem agir como inibidores da respiração celular, causar rápida parada de alimentação, perda das funções locomotoras, paralisia e morte (MENEZES, 2005). Além desses efeitos, um estudo observou que sementes de trigo tratadas com pó de folhas de $T$. purpurea causou repelência a Tribolium castaneum (Herbst 1797) (Coleoptera: Tenebrionidae) (PUGAZHVENDAN et al., 2009).

Algumas plantas ornamentais também podem ser consideradas tóxicas a humanos e a insetos, como ocorre com Nerium oleander L., conhecida como espirradeira, pertencente à família Apocynaceae, e que contém em suas folhas glicosídeos cardiotóxicos denominados oleandrina e neriantina (BARG, 2004). Extratos etanólicos preparados com folhas dessa espécie foram capazes de reduzir o tempo de sobrevivência de larvas de Muscina stabulans (Fallén) (Diptera: Muscidae), suprimir a oviposição e reduzir a longevidade de adultos (EL-SHAZLY; NASSAR; EL-SHERIEF, 1996).

Em meio às alternativas para o controle da broca-do-cafeeiro, umas das mais estudas é o fungo entomopatogênico Beauveria bassiana (Balsamo) (Vuillemin 1912) (Hypocreales: Cordycipitaceae), que ocorre naturalmente controlando populações desse inseto (NEVES; HIROSE, 2005). Essa espécie já foi observada em muitos países atacando H. hampei (MURPHY; MOORE, 1990), e também pode ser associada a outros métodos de controle, como os extratos vegetais, a fim de potencializar o controle, mas para tanto, é necessário que esses sejam seletivos ao fungo.

O objetivo deste trabalho foi avaliar, em laboratório, o efeito de $A$. indica, $M$. azedarach, $M$. oleifera, $T$. purpurea e $N$. oleander no controle e repelência da broca-do-cafeeiro, e os efeitos desses extratos sobre o desenvolvimento in vitro de $B$. bassiana.

\section{Material e Métodos}

O experimento foi conduzido em condições de laboratório, empregando-se adultos de H. hampei obtidos da criação do Instituto Agronômico do Paraná (IAPAR), onde os insetos foram mantidos em dieta artificial, por aproximadamente quatro meses em câmara climatizada $\left(25^{\circ} \mathrm{C} \pm 1\right.$ e fotofase de $12 \mathrm{~h})$.

\section{Coleta e preparo dos extratos vegetais}

As espécies vegetais foram coletadas no IAPAR - Estação Experimental de Londrina em julho de 2010, identificadas pela Dra. Ana Odete S. Vieira e incorporadas ao acervo do Herbário da Universidade Estadual de Londrina (F.U.E.L) (Tabela 1).

O material vegetal foi seco em estufa de circulação forçada de ar a $35^{\circ} \mathrm{C}$ até peso constante. Em seguida, as partes secas foram trituradas em liquidificador (Mallory $60 \mathrm{~Hz} 400 \mathrm{~W}$ ) até a trituração total. Esse pó vegetal foi misturado ao etanol e a água, ambos na concentração de $10 \%(\mathrm{p} / \mathrm{v})$, permanecendo em repouso por 24 horas $\left(25 \pm 1^{\circ} \mathrm{C}\right.$, no escuro) para a obtenção dos extratos. Após esse período, procedeu-se a filtragem utilizando papel 
filtro, e os sobrenadantes foram utilizados como extratos aquosos e etanólicos. O extrato etanólico obtido foi diluído em água destilada na concentração de $10 \%(\mathrm{v} / \mathrm{v})$.

Tabela 1. Espécies vegetais, parte vegetal, estádio fenológico e número de exsicata das plantas utilizadas para produção dos extratos etanólicos e aquosos.

\begin{tabular}{llll}
\hline \multicolumn{1}{c}{ Espécie vegetal } & \multicolumn{1}{c}{$\begin{array}{c}\text { Parte vegetal } \\
\text { coletada }\end{array}$} & \multicolumn{1}{c}{ Estádio fenológico } & $\begin{array}{c}\text { Número da } \\
\text { Exsicata }\end{array}$ \\
\hline Azadirachta indica & folha & terço médio de plantas adultas & 48848 \\
Melia azedarach & folha & terço médio de plantas adultas & 48845 \\
Moringa oleifera & folha, semente, raiz & terço médio de plantas adultas e mudas com 90 dias & 48847 \\
Tephrosia purpurea & folha, semente, raiz & terço médio de plantas adultas e mudas com 90 dias & 48846 \\
Nerium oleander & folha & terço médio de plantas adultas & 48844 \\
\hline
\end{tabular}

Fonte: Elaboração dos autores.

Mortalidade de H. hampei em folhas de cafeeiro tratadas com extratos vegetais antes da secagem da calda na superfície foliar

Folhas de cafeeiro (Coffea arábica) coletadas no terço médio de plantas adultas, na parte central dos ramos, foram transportadas até o laboratório, previamente desinfetadas em solução de hipoclorito a $1 \%$, e imergidas por 20 segundos em recipientes contendo $100 \mathrm{ml}$ de extratos vegetais etanólicos e aquosos (10\%) separadamente. Em seguida as folhas foram colocadas ainda úmidas, em tubos de vidro (2,5 cm de diâmetro x $8,5 \mathrm{~cm}$ altura) contendo uma tira $( \pm 0,5 \mathrm{~cm} \times 6,0 \mathrm{~cm})$ de papel filtro para absorver o excesso de extrato. Foram liberados dez insetos adultos no interior dos tubos, que em seguida foram vedados com filme de PVC, onde permaneceram em contato com as folhas tratadas. Após oito dias em câmara climatizada $\left(25 \pm 1^{\circ} \mathrm{C}\right.$ e fotofase de 12 h), foi avaliada a mortalidade. Os ensaios constaram de nove extratos etanólicos (sementes, folhas e raízes de $M$. oleifera e $T$. purpurea, e apenas folhas de $M$. azedarach, $N$. oleander e $A$. indica) oito aquosos (sementes, folhas e raízes de $M$. oleifera, sementes e folhas de T. purpurea, e apenas folhas de $M$. azedarach, $N$. oleander e $A$. indica) e um tratamento com inseticida sintético (endosulfan-300 $\mathrm{ml}$ do produto comercial/100 $\mathrm{L}$ - dose recomendada a campo) (AGROFIT, 2012). O delineamento experimental foi inteiramente casualizado em esquema fatorial $(2 \times 9)+1$ (solvente $\times$ espécies vegetais) + testemunha. Para as testemunhas as folhas foram imersas em água destilada esterilizada ou etanol. A parcela experimental foi constituída por dez insetos, com cinco repetições por tratamento.

Mortalidade de H. hampei em folhas de cafeeiro tratadas com extratos vegetais após a secagem da calda na superficie foliar

Após as avaliações realizadas no item anterior, os extratos que proporcionaram mortalidade superior a $40 \%$ foram testados seguindo a mesma metodologia. No entanto, para avaliar se a mortalidade ocorria apenas pelo contato direto entre o inseto e os extratos, ou também com o contato entre os insetos e as folhas após a evaporação dos extratos, as folhas de café, após tratadas, foram mantidas sobre papel toalha em condição ambiente, até que a superfície dessas estivesse totalmente seca para então serem acomodadas nos tubos juntamente com os insetos. Após oito dias em câmara climatizada $\left(25 \pm 1{ }^{\circ} \mathrm{C}\right.$ e fotofase de $12 \mathrm{~h}$ ), foi avaliada a mortalidade. O delineamento experimental foi inteiramente casualizado em esquema fatorial $(2 \times 5)+1$ (solvente $\times$ espécies vegetais) + testemunha aquosa ou etanólica, sendo cinco repetições de dez insetos. 
Foram empregadas cinco repetições por tratamento e a parcela experimental foi constituída por dez insetos.

\section{Teste de preferência com chance de escolha}

A arena experimental foi formada por uma caixa de poliestireno cristal tipo Gerbox ${ }^{\circledR}(11 \mathrm{x} 11 \mathrm{x}$ $3,5 \mathrm{~cm})$, contendo três placas de Petri $(4,5 \mathrm{~cm}$ de diâmetro) arranjadas de forma equidistante. Em uma das placas foram colocados dez frutos de café cereja (IAPAR 59), os quais foram imersos por 30 segundos nos extratos vegetais. Na placa ao lado, dez frutos previamente mergulhados apenas em água destilada ou em etanol, e na terceira placa, foram liberados dez brocas adultas. A avaliação foi realizada após quatro dias em câmara climatizada ( $25 \pm 1^{\circ} \mathrm{C}$ e fotofase de $12 \mathrm{~h}$ ), quantificando o número de brocas que penetraram nos grãos tratados e não tratados, bem como aquelas que não penetraram nos frutos. O delineamento foi inteiramente casualizado com quatro repetições e a parcela experimental constituída por dez insetos.

\section{Teste de preferência sem chance de escolha}

A arena foi constituída de duas placas de Petri, arranjadas em caixas Gerbox ${ }^{\circledR}(11 \times 11$ x 3,5 cm). Em uma das placas foram liberadas 10 brocas adultas, e na outra, 10 grãos de café cereja (IAPAR 59) previamente mergulhados nos extratos aquosos e etanólicos por 30 segundos. Os insetos foram mantidos em câmara climatizada $\left(25 \pm 1^{\circ} \mathrm{C}\right.$ e fotofase de $12 \mathrm{~h}$ ) e após quatro dias, foram realizadas as avaliações, onde o parâmetro avaliado foi o número de insetos que penetraram nos frutos tratados ou que permaneceram fora deles. $\mathrm{O}$ delineamento experimental foi inteiramente casualizado em esquema fatorial $(2 \times 9)+1$ (solvente $\times$ espécies vegetais) + testemunha aquosa ou etanólica, com quatro repetições, e a parcela experimental constituída por dez insetos.

\section{Efeito in vitro dos extratos a $B$. bassiana}

Avaliou-se in vitro a compatibilidade entre os extratos que causaram mortalidade para adultos de $H$. hampei superior a $40 \%$ e o isolado CG 425 de B. bassiana que foi pré-selecionado para o controle da broca-do-cafeeiro (NEVES; HIROSE, 2005). As variáveis analisadas foram: germinação dos conídios, unidades formadoras de colônias (UFC), crescimento vegetativo (CV) e produção/produtividade de conídios. Em placas de Petri (9 $\mathrm{cm}$ de diâmetro) contendo meio para produção de esporos (ME) (ALVES et al., 1998), foram aplicados $0,1 \mathrm{~mL}$ de cada extrato vegetal, separadamente. Em seguida, para a realização dos testes de germinação, em cada placa de Petri foi inoculada $0,1 \mathrm{ml}$ da suspensão de conídios de $B$. bassiana $\left(1 \times 10^{7}\right.$ conídios $\left.\mathrm{mL}^{-1}\right)$. Após 20 horas de incubação a $25^{\circ} \mathrm{C}$ foram quantificados os conídios germinados e não germinados através da observação em microscópio óptico (40X). Foram considerados como germinados os que apresentavam o tubo germinativo com comprimento igual ou superior ao conídio. Para determinar as UFC, foram aplicados $0,1 \mathrm{~mL}$ da suspensão de conídios $\left(1 \times 10^{3}\right.$ conídios $\mathrm{mL}-1)$ sobre o meio tratado com os extratos e quatro dias após a inoculação foram quantificadas a colônias formadas. Foram realizadas seis repetições por tratamento.

Para crescimento vegetativo, produção e produtividade de B. bassiana, os conídios foram inoculados na superfície do meio tratado em um único ponto central. Após 15 dias, o crescimento vegetativo foi obtido pelo diâmetro médio das colônias, a partir de medições perpendiculares. Para a produção de conídios, as colônias foram recortadas juntamente com o meio, suspensas em $20 \mathrm{~mL}$ de solução aquosa de Tween 20 a $0,005 \%$ $(\mathrm{v} / \mathrm{v})$, e submetidas à agitação em Vórtex durante um minuto. Em seguida, o número de conídios foi quantificado em câmara de Neubauer, obtendo-se a produção total e a produtividade, que foi estimada levando em consideração a divisão da produção de conídios pela área da colônia. Para essas variáveis 
foram realizadas quatro repetições. Na testemunha, as placas foram tratadas apenas com solução etanólica ou aquosa de Tween 20 a 0,005\% (v/v) substituindo os extratos.

\section{Análise estatística}

Os dados dos tratamentos em esquema fatorial foram submetidos à análise de variância, e as médias comparadas pelo teste de Tukey $(\mathrm{p}<0,05)$. Para verificar a diferença entre a mortalidade causada pelo tratamento químico com a mortalidade causada pelos extratos vegetais, a comparação entre as médias do fatorial com o tratamento químico endosulfan foi realizada pelo teste de Dunnett $(\mathrm{p}<0,05)$.

Para a análise no teste de preferência com chance de escolha se utilizou o Teste de Goodman para contrastes entre e dentro de proporções multinomiais $(\mathrm{p}<0,05)($ GOODMAN, 1964; 1965).
$\mathrm{O}$ índice de repelência $(\mathrm{RI})$ foi calculado com a formula $\mathrm{RI}=(\mathrm{C}-\mathrm{T}) /(\mathrm{C}+\mathrm{T}) \times 100$, onde $(\mathrm{C})$ é o número de insetos que penetraram nos grãos não tratados e $(\mathrm{T})$ o número de insetos que penetraram nos frutos tratados (VILLALOBOS; ROBLEDO, 1998).

\section{Resultados e Discussão}

Mortalidade de H. hampei em folhas de cafeeiro tratadas com extratos vegetais antes da secagem da calda na superfície foliar

Os maiores índices de mortalidade foram constatados nos tratamentos com extrato etanólico das sementes de $M$. oleifera $(62,00 \% \pm 2,00)$ e folhas de $T$. purpurea $(96,00 \% \pm 4,00)$, sendo esse último o único que não diferiu do tratamento químico com endosulfan $(100,00 \% \pm 0,00)$ (Tabela 2$)$.

Tabela 2. (\%) Mortalidade ( \pm erro padrão) de Hypothenemus hampei $(\mathrm{n}=50)$ no oitavo dia após contato com folhas de cafeeiro tratadas com extratos vegetais etanólicos e aquosos (antes da secagem da calda na superfície foliar).

\begin{tabular}{llclcl}
\hline Espécie Vegetal & Parte Utilizada & \multicolumn{2}{c}{ Extrato Etanólico $^{(1)}$} & Extrato Aquoso $^{(1)}$ & $\mathrm{ABb}$ \\
\hline Moringa oleifera & Folha & $48,00 \pm 8,60$ & $\mathrm{BCa}$ & $24,00 \pm 5,10$ & $\mathrm{Ab}$ \\
Moringa oleifera & Semente & $62,00 \pm 2,00$ & $\mathrm{ABa}$ & $56,00 \pm 15,03$ & $\mathrm{Aa}$ \\
Moringa oleifera & Raiz & $8,00 \pm 3,74$ & $\mathrm{DEa}$ & $6,00 \pm 6,00$ & $\mathrm{Ba}$ \\
Tephrosia purpurea & Folha & $96,00 \pm 4,00$ & $\mathrm{Aa}$ & $4,00 \pm 4,00$ & $\mathrm{Bb}$ \\
Tephrosia purpurea & Semente & $12,00 \pm 3,74$ & $\mathrm{CDEa}$ & $12,00 \pm 4,90$ & $\mathrm{Ba}$ \\
Tephrosia purpurea & Raiz & $36,00 \pm 4,00$ & $\mathrm{BCDE}$ & - & \\
Azadirachta indica & Folha & $44,00 \pm 14,70$ & $\mathrm{BCDa}$ & $12,00 \pm 5,83$ & $\mathrm{Bb}$ \\
Melia azedarach & Folha & $0,00 \pm 0,00$ & $\mathrm{~Eb}$ & $28,00 \pm 9,17$ & $\mathrm{ABa}$ \\
Nerium oleander & Folha & $34,00 \pm 16,91$ & $\mathrm{BCDEa}$ & $12,00 \pm 8,00$ & $\mathrm{Ba}$ \\
Testemunha & & $0,00 \pm 0,00$ & $\mathrm{Ea}$ & $6,00 \pm 4,00$ & $\mathrm{Ba}$ \\
\hline Endosulfan & & $100,00 \pm 0,00$ & & & \\
\hline
\end{tabular}

${ }^{(1)}$ Médias seguidas de mesma letra, maiúscula na coluna e minúscula na linha, não diferem entre si pelo teste de Tukey ( $\mathrm{p}<0,05$ ) $(\mathrm{CV}=68,14 \%)$ e seguidas de * não diferem do tratamento químico endossulfan pelo teste de Dunnett a $5 \%$ de probabilidade $(\mathrm{CV}=56,91 \%)$.

Fonte: Elaboração dos autores.

Espécies do gênero Tephrosia produzem funções locomotoras, paralisia e morte (VEITCH, substâncias com grande diversidade estrutural, 2007). Dentre os rotenóides, destaca-se a rotenona, incluindo os rotenóides, importantes isoflavonóides que é encontrada em maiores concentrações que manifestam propriedades inseticidas através nas raízes, mas pode também estar presente nas da imediata interrupção da alimentação, perda das folhas, ramos e sementes (MARICONI, 1981). 
Esse composto é muito utilizado no controle do besouro do Colorado, Leptinotarsa decemlineata (Coleoptera: Chrysomelidae), uma importante praga da batata no hemisfério norte (COSTA; BELO; BARBOSA, 1997).

Os diferentes tipos de solventes também podem causar alterações na atividade inseticida, como também foi verificado por Costa (1996), onde se constatou que extratos da raiz de timbó (Derris elliptica Benth) formulados com álcool etílico absoluto foram mais eficientes contra larvas de $4^{\circ}$ instar de Aedes aegypti (L.) (Diptera: Culicidae). Jaglan et al. (1997) também verificaram em seu estudo diferenças entre os solventes utilizados, onde extratos de sementes e folhas de $A$. indica, extraídos em clorofórmio/metanol, testados em Helicoverpa armigera (Hübner), apresentaram melhores resultados quando comparados aos extratos obtidos apenas com metanol. A menor atividade inseticida relacionada ao metanol pode estar relacionada à sua alta polaridade, onde uma maior quantidade de substâncias inativas, como açúcares e taninos, poderiam ter sido extraídas, e, portanto, causado uma diluição das substâncias ativas do extrato. Já o extrato de clorofórmio/ metanol, apresentando uma menor polaridade devido a maior concentração de clorofórmio, teria extraído uma menor quantidade de substâncias inativas.

As partes vegetais utilizadas nas formulações dos extratos também podem ser consideradas importantes, pois os compostos inseticidas das plantas não estão distribuídos uniformemente, o que pode ser a causa da variação na mortalidade dos insetos (SOUZA; VENDRAMIM, 2001). Esse fato foi verificado no presente estudo, onde os extratos de $M$. oleifera e T. purpurea apresentaram diferentes níveis de mortalidade conforme a parte vegetal utilizada (Tabela 2).

Os únicos extratos que se mostraram eficientes em ambos os solventes foram os de folhas e sementes de $M$. oleifera. A ação inseticida dessa espécie pode estar relacionada à presença de lectinas, classe de proteínas hemaglutinantes ou glicoproteínas de origem não imunológica que podem aglutinar células animais e/ou vegetais (CORREIA; COELHO; PAIVA, 2008). Estas proteínas são consideradas metabólitos importantes e podem atuar no mecanismo de defesa contra insetos e patógenos, causando efeitos degenerativos nas membranas celulares, e inibindo várias enzimas intestinais (RAMESHWARAM; NADIMPALLI, 2008).

Em um estudo realizado com lectinas purificadas de sementes de Canavalia brasiliensis Mart. Ex Benth (Fabaceae) e Cratylia floribunda Benth (Fabaceae) sobre Callosobruchus maculatus (Coleoptera: Bruchidae) foram constatados efeitos deletérios sobre o desenvolvimento desse inseto (FREITAS et al., 2011).

Mortalidade de H. hampei em folhas de cafeeiro tratadas com extratos vegetais após a secagem da calda na superficie foliar

Não foi possível observar diferença na mortalidade das brocas, antes e após a evaporação da calda da superfície foliar, mostrando que a ação inseticida dos extratos pode ocorrer no contato com as folhas úmidas e com as folhas secas. Este aspecto é particularmente importante no caso da broca do cafeeiro, pois o inseto passa a maior parte do tempo no interior dos frutos saindo dos mesmos para acasalar e fazer postura, e assim, ao caminhar pelas folhas e frutos, poderá sofrer o efeito inseticida dos extratos sem que haja o contato direto com o produto recém-aplicado.

Considerando-se a média de mortalidade provocada pelos tratamentos, todos os extratos promoveram percentuais de mortalidade superiores à testemunha. $\mathrm{O}$ extrato etanólico da folha de $T$. purpurea, tanto antes como após a secagem das caldas, manteve seu potencial inseticida (96 e $98 \%$ de mortalidade respectivamente) (Tabela 3 ). 
Tabela 3. Mortalidade (\%) ( \pm erro padrão) de Hypothenemus hampei $(\mathrm{n}=50)$ no oitavo dia de contato com folhas de cafeeiro tratadas com extratos vegetais etanólicos e aquosos (antes e após a secagem da calda na superfície foliar).

\begin{tabular}{llllll}
\hline Espécie Vegetal/ Extrato & $\begin{array}{c}\text { P a r } \\
\text { Utilizada }\end{array}$ & Antes-secagem & Pós-secagem $^{2}$ & \multicolumn{2}{c}{ Media $^{(1)}$} \\
\hline Moringa oleifera /etanólico & Folha & $48,00 \pm 8,60$ & $62,00 \pm 8,19$ & 55,00 & $\mathrm{~B}$ \\
Moringa oleifera /etanólico & Semente & $62,00 \pm 2,00$ & $32,00 \pm 8,19$ & 47,00 & $\mathrm{~B}$ \\
Moringa oleifera /aquoso & Semente & $56,00 \pm 15,03$ & $54,00 \pm 7,94$ & 55,00 & $\mathrm{~B}$ \\
Tephrosia purpurea /etanólico & Folha & $96,00 \pm 4,00^{*}$ & $98,00 \pm 1,42^{*}$ & 97,00 & $\mathrm{~A}$ \\
Azadirachta indica /etanólico & Folha & $44,00 \pm 14,70$ & $40,00 \pm 7,42$ & 42,00 & $\mathrm{~B}$ \\
Testemunha /etanólico & - & $0,00 \pm 0,00$ & $6,00 \pm 2,83$ & 3,00 & $\mathrm{C}$ \\
Testemunha / aquoso & - & $6,00 \pm 4,00$ & $10,00 \pm 3,16$ & 8,00 & $\mathrm{C}$ \\
Média $^{(1)}$ & - & 44,57 a & 43,14 a & & \\
\hline Endosulfan/aquoso & & $100,00 \pm 0,00$ & & \\
\hline
\end{tabular}

${ }^{(1)}$ Médias seguidas de mesma letra, maiúscula na coluna e minúscula na linha, não diferem entre si pelo teste de Tukey $(\mathrm{p}<0,05)$ $(\mathrm{CV}=45,11 \%)$ e seguidas de * não diferem do tratamento químico endossulfan pelo teste de Dunnett a $5 \%$ de probabilidade $(\mathrm{CV}=40,15 \%)$.

Fonte: Elaboração dos autores.

A ação inseticida causada apenas pelo contato entre os insetos e uma superfície tratada com os extratos também foi verificada por Fazolin et al. (2005), que testaram óleo de Piper aduncum L. sobre adultos de Cerotoma tingomarianus (Coleoptera: Chrysomelidae) em diferentes concentrações e apontaram que a aplicação em superfície contaminada (papel filtro) apresentou mortalidade superior em relação à aplicação tópica.

\section{Teste de preferência com chance de escolha}

Para os extratos etanólicos, a maior porcentagem de adultos que permaneceu externamente aos frutos foi observada para os tratamentos $A$. indica (folha$70,00 \%$ ) e T. purpurea (raiz- 67,50\%). Entre os frutos tratados e não tratados, a preferência das brocas foi pelos não tratados, exceto para os tratamentos M. oleifera (folha e semente), onde não se observou diferença (Tabela 4). Já para os extratos aquosos, a maior porcentagem de brocas que não penetrou nos frutos ocorreu para o tratamento $N$. oleander (folha- 80,00\%), M. azadarach (folha- 70,00\%) e T. purpurea (semente- 67,50\%). A preferência entre os frutos foi maior para os não tratados, exceto para os tratamentos T. purpurea (folha e semente) e $M$. azadarach (folha), onde não se observou diferença entre tratados e não tratados (Tabela 5). O fato dos insetos não penetrarem em nenhum fruto pode estar relacionado com a presença de compostos voláteis liberados por esses extratos, o que pode ter causando confusão nas brocas e impedido a localização dos frutos não tratados.

O comportamento de repelência dos insetos aos frutos tratados com extratos etanólicos e aquosos pode ser comprovada pelo Índice de Repelência (VILLALOBOS; ROBLEDO, 1998), onde são consideradas repelentes substâncias cujo índice está acima de 50. Verificou-se que todos os extratos etanólicos possuem ação repelente, sendo os maiores índices encontrados para os extratos oriundos de $M$. oleifera (raiz) e T. purpurea (semente), os quais foram encontrados índices de repelência de 85 e 80 respectivamente (Tabela 4). Para os extratos aquosos, $M$. oleifera (folha e semente) e $N$. oleander (folha) apresentaram índice de repelência igual a 100. Assim, estes extratos têm um elevado potencial para serem utilizados pelos produtores no manejo de populações de $H$. hampei. Apenas os extratos de T. purpurea (folha) e M. azedarach (folha) não apresentaram efeito repelente (Tabela 5). 
Tabela 4. Índice de repelência e preferência de Hypothenemus hampei $(\mathrm{n}=40)$ por frutos de cafeeiro tratados e não tratados com extratos vegetais etanólicos, ou permaneceram fora dos frutos, em teste com chance de escolha após quatro dias em contato com os frutos.

\begin{tabular}{|c|c|c|c|c|c|c|c|c|}
\hline \multirow{2}{*}{ Espécie Vegetal } & \multirow{2}{*}{ Parte Utilizada } & \multicolumn{6}{|c|}{ Preferência $^{(1)}$} & \multirow{2}{*}{ R.I $I^{(2)}$} \\
\hline & & \multicolumn{2}{|c|}{ Externo $^{(a)}$} & \multicolumn{2}{|c|}{ Tratado } & \multicolumn{2}{|c|}{ Não Tratado } & \\
\hline Moringa oleifera & Folha & 60,00 & $\mathrm{Ba}$ & 10,00 & $\mathrm{Ab}$ & 30,00 & $\mathrm{ABab}$ & 50,00 \\
\hline Moringa oleifera & Semente & 60,00 & $\mathrm{Ba}$ & 10,00 & $\mathrm{Ab}$ & 30,00 & $\mathrm{ABab}$ & 50,00 \\
\hline Moringa oleifera & Raiz & 32,50 & $\mathrm{Ba}$ & 5,00 & $\mathrm{Ab}$ & 62,50 & $\mathrm{Aa}$ & 85,00 \\
\hline Tephrosia purpurea & Folha & 45,00 & $\mathrm{Ba}$ & 7,50 & $\mathrm{Ab}$ & 47,50 & $\mathrm{ABa}$ & 73,00 \\
\hline Tephrosia purpurea & Semente & 50,00 & $\mathrm{Ba}$ & 5,00 & $\mathrm{Ab}$ & 45,00 & $\mathrm{ABa}$ & 80,00 \\
\hline Tephrosia purpurea & Raiz & 67,50 & $\mathrm{ABa}$ & 5,00 & Ac & 27,50 & $\mathrm{ABb}$ & 69,00 \\
\hline Azadirachta indica & Folha & 70,00 & $\mathrm{Aa}$ & 5,00 & Ac & 25,00 & $\mathrm{Bb}$ & 67,00 \\
\hline Melia azedarach & Folha & 62,50 & $\mathrm{Ba}$ & 5,00 & $\mathrm{Ab}$ & 32,50 & $\mathrm{ABa}$ & 73,00 \\
\hline Nerium oleander & Folha & 35,00 & $\mathrm{Bab}$ & 15,00 & $\mathrm{Ab}$ & 50,00 & $\mathrm{ABa}$ & 54,00 \\
\hline
\end{tabular}

(1) Porcentagens seguidas da mesma letra maiúscula na coluna e minúscula na linha, não diferem significativamente entre as proporções pelo teste de proporção de Goodman para contrastes dentro e entre multinomiais $(\mathrm{p}<0,05)$

(2) R.I, Índice de Repelência

(a) porcentagem de insetos que permaneceram no local de origem e não penetraram nos frutos

Fonte: Elaboração dos autores.

Tabela 5. Índice de repelência e preferência de Hypothenemus hampei $(\mathrm{n}=40)$ aos frutos de café tratados e não tratados com extratos vegetais aquosos, ou permaneceram fora dos frutos, em teste com chance de escolha após quatro dias em contato com os frutos.

\begin{tabular}{|c|c|c|c|c|c|c|c|c|}
\hline \multirow{2}{*}{ Espécie Vegetal } & \multirow{2}{*}{ Parte Utilizada } & \multicolumn{6}{|c|}{ Preferência $^{(1)}$} & \multirow{2}{*}{ R.I $I^{(2)}$} \\
\hline & & \multicolumn{2}{|c|}{ Externo } & \multicolumn{2}{|c|}{ Tratado } & \multicolumn{2}{|c|}{ Não Tratado } & \\
\hline Moringa oleifera & Folha & 32,50 & $\mathrm{Ca}$ & 0,00 & $\mathrm{Bb}$ & 67,50 & $\mathrm{Aa}$ & 100,00 \\
\hline Moringa oleifera & Semente & 55,00 & $\mathrm{ABCa}$ & 0,00 & $\mathrm{Bb}$ & 45,00 & $\mathrm{ABa}$ & 100,00 \\
\hline Moringa oleifera & Raiz & 40,00 & $\mathrm{BCa}$ & 7,50 & $\mathrm{ABb}$ & 52,50 & $\mathrm{ABa}$ & 75,00 \\
\hline Tephrosia purpurea & Folha & 50,00 & $\mathrm{ABCa}$ & 22,50 & $\mathrm{Aa}$ & 27,50 & $\mathrm{Ba}$ & 10,00 \\
\hline Tephrosia purpurea & Semente & 67,50 & $\mathrm{ABCa}$ & 2,50 & $\mathrm{Abc}$ & 30,00 & $\mathrm{Bb}$ & 85,00 \\
\hline Azadirachta indica & Folha & 47,50 & $\mathrm{ABCa}$ & 5,00 & $\mathrm{ABb}$ & 47,50 & $\mathrm{ABa}$ & 81,00 \\
\hline Melia azedarach & Folha & 70,00 & $\mathrm{ABa}$ & 10,00 & $\mathrm{ABb}$ & 20,00 & $\mathrm{Bb}$ & 33,00 \\
\hline Nerium oleander & Folha & 80,00 & $\mathrm{Aa}$ & 0,00 & $\mathrm{Bc}$ & 20,00 & $\mathrm{Bb}$ & 100,00 \\
\hline
\end{tabular}

${ }^{(1)}$ Porcentagens seguidas da mesma letra maiúscula na coluna e minúscula na linha, não diferem significativamente entre as proporções pelo teste de proporção de Goodman para contrastes dentro e entre multinomiais $(\mathrm{p}<0,05)$

(2) R.I, Índice de Repelência

Fonte: Elaboração dos autores.

Teste de preferência sem chance de escolha

Os extratos de $A$. indica (folhas) foram responsáveis pela menor porcentagem $(31,25 \%)$ de insetos internos aos frutos, contrastando com $T$. purpurea (raiz) onde $70 \%$ das brocas permaneceram dentro dos frutos. Ambos os tratamentos diferiram da testemunha, onde se observou 83,75\% dos insetos no interior dos frutos. Não houve diferença entre extrato etanólico e aquoso. (Tabela 6). 
Tabela 6. Porcentagem ( \pm erro padrão) de Hypothenemus hampei $(\mathrm{n}=40)$ internas aos frutos de café tratados com extratos vegetais etanólicos e aquosos em teste sem chance de escolha após quatro dias em contato com os frutos.

\begin{tabular}{llllll}
\hline \multirow{2}{*}{ Espécie Vegetal } & \multirow{2}{*}{ Parte Utilizada } & \multicolumn{3}{l}{ Insetos internos ao grão tratado (\%) } & \\
\cline { 3 - 6 } & & Extrato Etanólico & ExtratoAquoso & Média $^{(1)}$ & \\
\hline Moringa oleifera & Folha & $52,50 \pm 8,54$ & $45,00 \pm 5,00$ & 48,75 & $\mathrm{ABC}$ \\
Moringa oleifera & Semente & $52,50 \pm 4,79$ & $45,00 \pm 6,45$ & 48,75 & $\mathrm{ABC}$ \\
Moringa oleifera & Raiz & $50,00 \pm 4,08$ & $60,00 \pm 0,00$ & 55,00 & $\mathrm{ABC}$ \\
Tephrosia purpurea & Folha & $37,50 \pm 13,15$ & $60,00 \pm 18,26$ & 48,75 & $\mathrm{ABC}$ \\
Tephrosia purpurea & Semente & $50,00 \pm 14,72$ & $60,00 \pm 10,80$ & 55,00 & $\mathrm{ABC}$ \\
Tephrosia purpurea & Raiz & $70,00 \pm 12,25$ & - & 70,00 & $\mathrm{AB}$ \\
Azadirachta indica & Folha & $37,50 \pm 13,15$ & $25,00 \pm 9,57$ & 31,25 & $\mathrm{C}$ \\
Melia azedarach & Folha & $50,00 \pm 8,16$ & $45,00 \pm 11,90$ & 47,50 & $\mathrm{BC}$ \\
Nerium oleander & Folha & $60,00 \pm 16,33$ & $60,00 \pm 4,08$ & 60,00 & $\mathrm{ABC}$ \\
Testemunha & - & $87,50 \pm 2,50 *$ & $80,00 \pm 5,77^{* *}$ & 83,75 & $\mathrm{~A}$ \\
Média $^{(1)}$ & - & $54,75 \mathrm{a}$ & $53,33 \mathrm{a}$ & & \\
\hline
\end{tabular}

${ }^{(1)}$ Médias seguidas da mesma letra maiúscula na coluna e minúscula na linha, não diferem entre si pelo teste Tukey $(\mathrm{p}<0,05)$ $(\mathrm{CV}=37,91 \%)$

*Testemunha apenas com etanol

** Testemunha apenas com água

Fonte: Elaboração dos autores.

Esses resultados corroboram com estudos de Rodrígues-Lagunes et al. (1998), onde foi observada repelência de insetos adultos de $H$. hampei ao alimento tratado com óleo de nim. Além da repelência, Sponagel (1994), também observou em condições de laboratório e campo, a redução na alimentação e morte desses insetos quando submentidos ao contato com óleo de nim. Esse efeito de $A$. indica pode ser explicado por um de seus compostos, a azadiractina, que além de ser tóxica a insetos, também tem efeito de repelência (MORDUE; BLACKWELL, 1993).

\section{Efeito in vitro dos extratos à B. bassiana}

A germinação dos conídios foi menor para os extratos etanólicos provenientes de folhas e sementes de $M$. oleifera, que foi respectivamente $48,70 \% \pm 4,95$ e $74,53 \% \pm 3,26$. Já para o tratamento com extrato aquoso de semente de $M$. oleifera a germinação foi de $88,32 \%$. Os extratos etanólicos oriundos da folha de $T$. purpurea e $A$. indica obtiveram os maiores valores de germinação, $99,45 \% \pm 0,29$ e $98,14 \% \pm 0,46$, respectivamente, não diferindo da testemunha etanólica $(99,50 \% \pm$ $0,10)$ e aquosa $(98,84 \% \pm 0,10)$ (Tabela 7$)$.

A redução na porcentagem de germinação pode indicar apenas um atraso, pois as demais variáveis de desenvolvimento, especialmente as UFC, não sofreram alterações em relação à testemunha. Esse atraso na germinação pode ser devido à ação fungistática registrada para $M$. oleifera (CHUANG et. al., 2007). Entretanto, é possível que tenha ocorrido, com o passar do tempo, degradação dessas substâncias, que deixariam de inibir a germinação.

A interferência de extratos de plantas no desenvolvimento de $B$. bassiana foi verificada em trabalhos que mostraram o efeito fungitóxico de óleo de nim sobre o fungo na redução na germinação, diâmetro de colônia e conidiogênese (HIROSE; NEVES; ZEQUI, 2001). Em outro estudo, um produto à base de óleo de sementes de nim inibiu a produção de conídios de $B$. bassiana em $96,6 \%$, porém, extratos aquosos de sementes e de folhas de nim mostraram-se compatíveis com o entomopatógeno em todas as concentrações testadas (MARQUES; MONTEIRO; PEREIRA, 2004). Os extratos de plantas devem ser seletivos 
tanto aos fungos entomopatogênicos que ocorrem naturalmente, quanto aos que são introduzidos, a fim de conservar sua viabilidade para o controle de insetos (OLIVEIRA; NEVES; KAWAZOE, 2003).

Os extratos vegetais estudados mostram-se como uma opção para o manejo da broca, e associados a outras práticas, podem contribuir para a redução de aplicações de inseticidas químicos sintéticos, que apresentam problemas aos organismos benéficos e ao meio ambiente. Entretanto, devem ser testados em condições de campo, onde os fatores ambientais podem ser limitantes para a eficiência dos extratos.

Tabela 7. Efeito de extratos vegetais etanólicos e aquosos sobre o fungo Beauveria bassiana, em cinco variáveis do desenvolvimento in vitro ${ }^{(1)}$.

\begin{tabular}{|c|c|c|c|c|c|c|c|}
\hline $\begin{array}{c}\text { Espécie Vegetal/ } \\
\text { Extrator }\end{array}$ & $\begin{array}{c}\text { Parte } \\
\text { Utilizada }\end{array}$ & Germinação & (2) UFC & & ${ }^{(3)} \mathrm{C} \mathrm{V}$ & Produção & Produtividade \\
\hline $\begin{array}{l}\text { Moringa } \\
\text { oleifera / } \\
\text { etanólico }\end{array}$ & Folha & $48,70 \pm 4,95 \mathrm{~d}$ & $68,00 \pm 3,31$ & $\mathrm{a}$ & $27,12 \pm 2,95 \mathrm{~b}$ & $2141,25 \pm 198,38 a$ & $80,45 \pm 7,11 \quad a$ \\
\hline $\begin{array}{l}\text { Moringa } \\
\text { oleifera / } \\
\text { etanólico }\end{array}$ & Semente & $74,53 \pm 3,26 \mathrm{c}$ & $75,00 \pm 5,37$ & $\mathrm{a}$ & $32,66 \pm 0,29 \mathrm{ab}$ & $2205,00 \pm 361,05 a$ & $67,76 \pm 11,58 \mathrm{a}$ \\
\hline $\begin{array}{l}\text { Moringa } \\
\text { oleifera / } \\
\text { aquoso }\end{array}$ & Semente & $88,32 \pm 1,03 \mathrm{~b}$ & $72,00 \pm 3,90$ & $\mathrm{a}$ & $33,17 \pm 0,00 \mathrm{ab}$ & $1567,50 \pm 168,18 a$ & $47,26 \pm 5,07 \quad a$ \\
\hline $\begin{array}{l}\text { Tephrosia } \\
\text { purpurea / } \\
\text { etanólico }\end{array}$ & Folha & $99,45 \pm 0,29 a$ & $82,00 \pm 8,81$ & $\mathrm{a}$ & $35,27 \pm 1,15 \mathrm{a}$ & $2197,50 \pm 364,11 a$ & $61,91 \pm 9,31 \quad a$ \\
\hline $\begin{array}{l}\text { Azadirachta } \\
\text { indica / } \\
\text { etanólico }\end{array}$ & Folha & $98,14 \pm 0,46 \quad a b$ & $83,50 \pm 3,70$ & $\mathrm{a}$ & $33,94 \pm 0,50 \mathrm{ab}$ & $1916,25 \pm 324,32 a$ & $56,56 \pm 9,58 \quad a$ \\
\hline $\begin{array}{l}\text { Testemunha / } \\
\text { etanólico }\end{array}$ & - & $99,50 \pm 0,10 a$ & $77,00 \pm 6,05$ & $\mathrm{a}$ & $28,36 \pm 1,92 \mathrm{ab}$ & $2080,00 \pm 244,70 a$ & $75,50 \pm 13,46 a$ \\
\hline $\begin{array}{l}\text { Testemunha/ } \\
\text { aquoso }\end{array}$ & - & $98,84 \pm 0,10 \quad a$ & $72,00 \pm 4,11$ & $\mathrm{a}$ & $30,10 \pm 2,57 \mathrm{ab}$ & $1502,50 \pm 216,15 a$ & $49,13 \pm 3,41 \quad a$ \\
\hline CV (\%) & & 6,44 & 17,29 & & 10,91 & 28,63 & 29,10 \\
\hline
\end{tabular}

${ }^{(1)}$ Médias ( \pm erro-padrão) seguidas da mesma letra na coluna não diferem entre si pelo teste Tukey $(\mathrm{p}<0,05)$. ${ }^{(2)} \mathrm{UFC}$, unidades formadoras de colônias; ${ }^{(3)} \mathrm{CV}$, crescimento vegetativo; $\mathrm{CV}(\%)$, coeficiente de variação.

Fonte: Elaboração dos autores.

\section{Conclusões}

Os extratos etanólicos T. purpurea (folha), etanólicos e aquosos de M. oleifera (semente) obtiveram maior ação letal para H. hampei.

Para efeito de repelência sobre a broca-docafeeiro apenas os extratos aquosos de T. purpurea (folha) e M. azedarach (folha) não foram eficientes.

O extrato etanólico de T. purpurea (folha) não afetou a germinação de $B$. bassiana, o que permite sua associação no controle de H. hampei.

\section{Agradecimentos}

Ao $\mathrm{CNPq}$ pela bolsa de mestrado concedida ao primeiro autor, pesquisadora doutora do Instituto Agronômico do Paraná Ana Maria Meneguim por fornecer os insetos e a professora doutora da Universidade Estadual de Londrina Ana Odete S. Vieira pela identificação das espécies vegetais. 


\section{Referências}

AGÊNCIA NACIONAL DE VILÂNCIA SANITÁRIA - ANVISA. Programa de análise de resíduos de agrotóxicos em alimentos (PARA). Brasília, Anvisa, 2010. 22 p. Disponível em: <http://portal.anvisa.gov.br/ wcm/comcect>. Acesso em: 11 abr. 2012.

AGROFIT Agrofit: sistema de agrotóxicos fitossanitários. Disponível em: <http://extranet.agricutura.gov.br/ agrofit_cons/principal_agrofit_cons.>. Acesso em: 11 abr. 2012.

ALVES, S. B.; ALMEIDA, J. E. M.; MOINO JUNIOR, A.; ALVES, L. F. A. Técnicas de laboratório. In: ALVES, S. B. (Ed.). Controle microbiano de insetos. Piracicaba: FEALQ, 1998. p. 637-712.

BARG, D. G. Plantas tóxicas. 2004. Monografia (Metodologia científica- Fitoterapia) - Faculdade de Ciências da Saúde. Universidade de São Paulo, São Paulo.

BRUN, L. O.; MARCILLAUD, C.; GAUDICHON, V.; SUCKLING, D. M. Endosulfan resistance in Hypothenemus hampei (Coleoptera: Scolytidae) in New Caledonia. Journal of Economic Entomology, Maryland, v. 82, n. 5, p. 1311-1316, 1989.

CHUANG, P. H.; LEE, C. W.; CHOU, J. Y.; MURUGAN, M.; SHIEN, B. J.; CHEN, H. M. Anti-fungal activity of crude extracts and essential oil of Moringa oleifera Lam. Bioresource Technology, Florida, v. 98, n. 1, p. 232-236, 2007.

COMPANHIA NACIONAL DE ABASTECIMENTO CONAB. Acompanhamento da safra Brasileira café. Safra 2011. Primeira estimativa, janeiro/2011. Brasília: Conab, 2011. 25 p. Disponível em: <http://www.conab.gov.br/ OlalaCMS/uploads/arquivos /11_01_06_08_52_41_ boletim_cafe 1a_estimativa_safra_2011.pdf $>$. Acesso em: 11 abr. 2012.

CORREIA, M. T. S.; COELHO, L. C. B. B.; PAIVA, P. M. G.. Lectins, carbohydrate recognition molecules: are they toxic? In: SIDDIQUE, Y. H. (Ed.). Recent trends in toxicology. Kerala: Transworld Research Network, 2008. v. 37 , p. $47-59$.

COSTA, J. P. C. Efeito da variabilidade de timbós de diferentes regiões da Amazônia em Musca domestica L. (DÍPTERA: Muscidae). 1996. Dissertação (Mestrado em em Genética e Melhoramento de Plantas) - Faculdade de Ciências Agrárias e Veterinárias, Jaboticabal.

COSTA, J. P. da; BELO, M.; BARBOSA, J. C. Efeito de espécies de timbó (Derris spp.: Fabaceae) em populações de Musca domestica L. Annais da Sociedade Entomológica do Brasil, Londrina, v. 26, n. 1, p. 163168, 1997.
EL-SHAZLY, M. M.; NASSAR, M. I.; EL-SHERIEF, H. A. Toxic effect of ethanolic extract of Nerium oleander (Apocynaceae) leaves against different developmental stages of Muscina stabulans (Diptera-Muscidae). Journal of the Egyptian Society of Parasitology, Cairo, v. 26, n. 2, p. 461-473, 1996.

FAZOLIN, M.; ESTRELA, J. L. V.; CATANI, V.; LIMA, M. S.; ALECIO, M. R. Toxidade do óleo de Piper aduncum L. a adultos de Cerotoma tingomarianus Bechyne (Coleoptera: Chrysomelidae). Neotropical Entomology, Londrina, v. 34, n. 3, p. 485-489, 2005.

FERREIRA, P. M. P.; CARVALHO, A. F. U.; FARIAS, D. F.; CARIOLANO, N. G.; MELO, V. M. M.; QUEIROZ, M. G. R.; MARTINS, A. M. C.; MACHADO-NETO, J. G. Larvicidal activity of the water extract of Moringa oleifera seeds against Aedes aegypti and its toxicity upon laboratory animals". Anais da Academia Brasileira de Ciências, Rio de Janeiro, v. 81, n. 2, p. 207-216, 2009.

FRANCO-FRAGUAS, L.; PLÁ, A.; FERREIRA, F.; MASSALDI, H.; SUÁREZ, N.; VIERA, F. B. Preparative purification of soybean agglutinin by affinity chromatography and its immobilization for polysaccharide isolation. Journal of Chromatography B., Amsterdam, v. 790, n. 1, p. 365-72, 2003.

FREITAS, C. D. T.; RAMOS, M. V.; SOUZA, D. P.; MARINHO, J. D. B.; TEIXEIRA, F. M.; OLIVEIRA, J. S. Correlações entre atividade inseticida e resistência a proteólise de duas lectinas vegetais glicose/manose. Comunicata Scientiae, Bom Jesus, v. 2, n. 1, p. 34-41, 2011.

GALLO, D.; KANANO, O.; SILVEIRA NETO, S.; CARVALHO, R. P. L.; BAPTISTA, G. C.; BERTI FILHO, E.; PARRA, J. R. P.; ZUCCHI, R. A.; ALVES, S. B.; VENDRAMIM, J. D.; MARCHINI, L. C.; LOPES, J. R. S.; OMOTO, C. Manual de entomologia agrícola. Piracicaba: FEALQ, 2002. 920 p.

GINGERICH, D. P.; BORSA, P.; SUCKLING, D. M.; BRUN, L. O. Inbreeding in the coffee berry borer, Hypothenemus hampei (Coleoptera: Scolytidae) estimated from endosulfan resistance phenotype frequences. Bulletin of Entomological Research, Cambridge, v. 86, n. 6, p. 667-674, 1996.

GOODMAN, L. A. On simultaneous confidence intervals for contrasts among multinomial proportions. Technometrics, Alexandria, v. 7, n. 2, p. 247-254, 1965.

. Simultaneous confidence intervals for contrasts among multinomial populations. Annals of Mathematical Statistics, Ohio, v. 35, n. 2, p. 716-725, 1964.

HIROSE, E.; NEVES, P. M. O. J.; ZEQUI, J. A. C. Effect of biofertilizers and neem oil on the entomopathogenic 
fungi Beauveria bassiana (Bals.) Vuill. and Metarhizium anisopliae (Metsch.) Sorok. Brazilian Archives of Biology Technology, Curitiba, v. 44, n. 4, p. 419-423, 2001.

JAGLAN, M. S.; KHOKHAR, K. S.; MALIK, M. S.; SINGH, R. Evaluation of neem (Azadirachta indica A. Juss) extracts against american bollworm, Helicoverpa armigera (Hübner). Journal of Agricultural and Food Chemistry, Washington, v. 45, n. 8, p. 3262-3268, 1997.

MARICONI, F. A. M. Inseticidas e seu emprego no combate às pragas: com uma introdução sobre o estudo dos insetos. 5. ed. São Paulo: Nobel, 1981. 130 p.

MARQUES, R. P.; MONTEIRO, A. C.; PEREIRA, G. T. Crescimento, esporulação e viabilidade de fungos entomopatogênicos em meios contendo diferentes concentrações de óleo de nim (Azadirachta indica). Ciência Rural, Santa Maria, v. 34, n. 6, p. 1675-1680, 2004.

MENEZES, E. L. A. Inseticidas botânicos: seus princípios ativos, modo de ação e uso agrícola. Rio de Janeiro: Seropédica, 2005. (Embrapa, Documentos 205).

MORDUE, A. J. M.; BLACKWELL, A. Azadirachtin: an update. Journal of Insect Physiology, Oxford, v. 39, n. 11, p. 903-924, 1993.

MURPHY, S. T.; MOORE, D. Biological control of the coffee berry borer, Hypothenemus hampei (Ferrari) (Coleoptera, Scolytidae): previous programmes and possibilities for the future. Biocontrol News and Information, United Kingdon, v. 11, n. 2, p. 107-117, 1990.

NEVES, P. M. O. J.; HIROSE, E. Seleção de isolados de Beauveria bassiana para o controle biológico da brocado-café, Hypothenemus hampei (Ferrari) (Coleoptera: Scolytidae). Neotropical Entomology, Londrina, v. 34, n. 1, p. 77-82, 2005.

OLIVEIRA, C. N.; NEVES, P. M. O. J.; KAWAZOE, L. S. Compatibility between the entomopathogenic fungus Beauveria bassiana and insecticides used in coffee plantations. Scientia Agricola, Piracicaba, v. 60, n. 4, p. 663-667, 2003.

PUGAZHVENDAN, S. R.; ELUMALAI, K.; ROSS, R. P.; SOUNDARARAJAN, M. Repellent activity of chosen plant species against Tribolium castaneum. World Journal of Zoology, Egypt, v. 4, n. 3, p. 188-190, 2009.

RAMESHWARAM, N. R.; NADIMPALLII, S. K. An efficient method for the purification and quantification of a galactose-specific lectin from vegetative tissues of Dolichos lablab. Journal of Chromatography B, Amsterdam, v. 861, n. 2, p. 209-217, 2008.

REIS, P. R. Prejuízo certo. Revista Cultivar, Pelotas, v. 4, n. 38, p. 10-13, 2002.
RODRÍGUES-LAGUNES, D. A.; LAGUNES-TEJEDA, A.; RIESTRO-DIAZ， D.; RODRÍGUES-MACIEL, C.; VELÁSQUEZ-MENDOZA, J.; BECERRIL, R. E.; PACHECO-VELASCO, E. Extractos acuosos de nim para el combate de la broca de café. Manejo Integrado de Plagas, Costa Rica, v. 49, n. 2, p. 73-77, 1998.

SAITO, M. L. As plantas praguicidas, alternativa para o controle de pragas na agricultura. Jaguariúna, SP: Embrapa, 2004. 3 p. (Informativo Embrapa Meio Ambiente, v. 26).

SANTOS, B. S.; FARIAS, P. M. A.; MENEZES, F. D.; FERREIRA, R. C.; ALVES JÚNIOR, S.; FIGUEIREDO, R. C. B. Q.; BELTRÃO, E. I. C. Lectin functionalized quantum dots for recognition of mammary tumors. Procedings of SPIE, San Diego, v. 6096, n. 4, p. 1J-8J, 2006.

SCHMUTTERER, H. Properties and potential of natural pesticides from the neem tree Azadirachta indica. Annual Review of Entomology, Palo Alto, v. 35, n. 1, p. 271-297, 1990.

SOUZA, A. P.; VENDRAMIM, J. D. Atividade inseticida de extratos aquosos de meliaceae sobre a moscabranca Bemisia tabaci (Genn.) biótipo B (Hemíptera; aleyrodidae). Neotropical Entomology, Londrina, v. 30, n. 1, p. 133-137, 2001.

SPONAGEL, K. W. La broca del caf. Hypotenemus hampei em plantaciones de caf. Robusta en La Amazon.a Ecuatoriana. Wissenschaftlicher: Huyesen, 1994. 185 p.

VALLADARES, G.; DEFAGO, M. T.; PALACIOS, S. Laboratory evaluation of Melia azedarach (Meliaceae) extracts against the elm leaf beetle (Coleoptera:Chrysomelidae). Journal of Economic Entomology, Lanham, v. 90, n. 3, p. 747-750, 1997.

VEITCH, N. C. Isoflavonoids of the leguminosa. Natural Products Reports, Lanham, v. 24, n. 8, p. 416-464, 2007.

VENTURA, M. U.; ITO, M. Antifeedant activity of Melia azedarach (L.) extracts to Diabrotica speciosa (Genn.) (Coleoptera: Chrysomelidae) beetles. Brazilian Archives of Biology and Technology, Curitiba, v. 2, n. 43, p. 215-219, 2000.

VILLALOBOS, M. J. P.; ROBLEDO, A. Screening for anti-insect activity in mediterranean plants. Industrial Crops and Products, Netherlands, v. 8, n. 3, p. 183-194, 1998.

WIESBROOK, M. L. Natural indeed: are natural insecticides safer and better than conventional insecticides? Illinois Pesticide Review, Urbana, v. 17, n. 3, p. 1-8, 2004. 
